\title{
Adequação nutricional das refeições consumidas por adolescentes de instituição filantrópica de Belo Horizonte
}

Nutritional adequacy of meals consumed by adolescents of a philanthropic institution in Belo Horizonte

Adecuación nutricional de las comidas consumidas por adolescentes de uma institución filantrópica em Belo Horizonte

Talita Vieira Botinha Macedo

ORCID: https://orcid.org/0000-0003-0677-5838 Centro Universitário Una, Brasil E-mail: tlitamacedo94@gmail.com

Érica Taís de Assis Batista

ORCID: https://orcid.org/ 0000-0001-6653-840X Centro Universitário Una, Brasil E-mail: ericatai10@hotmail.com

Marriethe de Oliveira Carneiro ORCID: https://orcid.org/ 0000-0001-7336-0259 Centro Universitário Una, Brasil

E-mail: marrietheoliveira1986@gmail.com Bárbara Pereira da Silva ORCID: https://orcid.org/ 0000-0002-4633-4183 Centro Universitário Una, Brasil E-mail: barbara_p.s@hotmail.com

Maria Marta Amancio Amorim

ORCID: https://orcid.org/ 0000-0001-8268-2508 Centro Universitário Unifacvest, Brasil Centro de Estudos em Migrações e Relações Interculturais, Portugal E-mail: martamorim@hotmail.com

\begin{abstract}
Resumo
O estudo teve como objetivo avaliar o consumo alimentar de adolescentes de uma instituição filantrópica de Belo Horizonte, Brasil. A alimentação adequada na adolescência é fundamental para os jovens que passam a maior parte do dia em escolas integrais. Participaram do estudo cerca de 600 adolescentes, com idade entre 13 a 17 anos. Analisaramse de forma qualitativa as refeições, durante vinte dias, utilizando o método de Avaliação Qualitativa das Preparações do Cardápio. E para análise quantitativa empregou-se a pesagem direta do almoço durante sete dias e para os lanches utilizaram-se as quantidades per capita. As recomendações do Programa Nacional de Alimentação Escolar foram empregadas como parâmetro para analisar o consumo dos adolescentes de acordo com faixa etária, em período integral. Constatou-se insuficiente consumo dos carboidratos, proteínas, lipídeos, energia, fibra, ferro, magnésio, zinco, vitamina A, e vitamina $\mathrm{C}$, para ambas as faixas etárias. O ambiente escolar atua como meio de promoção a saúde dos adolescentes. Diante deste contexto surge a necessidade de intervenções nessas populações a fim de garantir uma alimentação equilibrada de acordo com cada faixa etária, identificando os agravos nutricionais e os grupos de risco, promovendo assim a saúde dos adolescentes.
\end{abstract}

Palavras-chave: Consumo de alimentos; Adolescente; Alimentação escolar.

\begin{abstract}
Considering the importance of an adequate diet in adolescence and that many young people spend most of the day in whole schools, the study aimed to evaluate the food consumption of adolescents from a philanthropic institution in Belo Horizonte, MG. About 600 adolescents, aged 13 to 17 years, participated in the study. The meals were qualitatively analyzed for 20 days using the method of Qualitative Evaluation of the Menu Preparations. And for quantitative analysis the direct weighing of the lunch was used during seven days. Per capita quantities were used for the snacks. The recommendations of the National School Feeding Program were used as a parameter to analyze the consumption of adolescents according to age, full time. It was found insufficient consumption of carbohydrates, proteins, lipids, energy, fiber, iron, magnesium, zinc, vitamin A, and vitamin C, for both age groups. The school environment acts as a means of promoting the health of adolescents. Given this context, there is a need for
\end{abstract}


interventions in these populations in order to guarantee a balanced diet according to each age group, identifying nutritional diseases and groups at risk, thus promoting the health of adolescents.

Keywords: Food consumption; Adolescent; School feeding.

\section{Resumen}

El estudio tuvo como objetivo evaluar la ingesta de adolescentes de una institución filantrópica en Belo Horizonte, Brasil. Una nutrición adecuada en la adolescencia es esencial para los jóvenes que pasan la mayor parte del día en escuelas completas. Alrededor de 600 adolescentes, de entre 13 y 17 años, participaron en el estudio. Las comidas se analizaron cualitativamente durante veinte días utilizando el método de evaluación cualitativa de los preparativos del menú. Y para el análisis cuantitativo, se utilizó el pesaje directo del almuerzo durante siete días y para los bocadillos se utilizaron las cantidades per cápita. Las recomendaciones del Programa Nacional de Alimentación Escolar se utilizaron como parámetro para analizar el consumo de adolescentes según el grupo de edad, a tiempo completo. No hubo consumo suficiente de carbohidratos, proteínas, lípidos, energía, fibra, hierro, magnesio, zinc, vitamina A y vitamina C, para ambos grupos de edad. El entorno escolar actúa como un medio para promover la salud de los adolescentes. En este contexto, es necesario realizar intervenciones en estas poblaciones para garantizar una dieta equilibrada según cada grupo de edad, identificando problemas nutricionales y grupos de riesgo, promoviendo así la salud de los adolescentes.

Palabras clave: Consumo de alimentos; Adolescente; Alimentación escolar.

\section{Introdução}

A adolescência consiste em um período de mudança entre a infância e a idade adulta, sendo uma fase do ciclo vital caracterizada por importantes transformações biológicas, sociais e comportamentais. A alimentação adequada contribui para o crescimento, o desenvolvimento dos adolescentes, a redução dos riscos de doenças crônicas não transmissíveis nas fases adulta e idosa, proporcionando assim melhor qualidade de vida e melhoria do estado nutricional (Santana et al. 2015).

Entre 10 a 14 anos ocorrem as mudanças puberais e o fim da fase de crescimento, resultando numa grande demanda de nutrientes fundamentais para o completo desenvolvimento dos adolescentes. A imagem corporal, a situação financeira familiar, os alimentos consumidos fora de casa, os alimentos industrializados, a influência da mídia e a disponibilidade do alimento podem moldar os hábitos dos adolescentes e influenciar suas escolhas. Isso está fortemente ligado aos adolescentes de mesma faixa etária, que adquirem hábitos alimentares inadequados adotados pelo grupo que a qual pertence (Bertin et al, 2008).

A alimentação adequada das crianças e dos adolescentes é um suporte fundamental para o crescimento, pois a ingestão insuficiente de nutrientes pode retardar o início do desenvolvimento puberal, prejudicando o ganho de estatura. A condição nutricional na adolescência depende da ingestão adequada de nutrientes de acordo com as necessidades nutricionais na infância. É fundamental incentivar a alimentação saudável precocemente, associada à atividade física, para que esses comportamentos se consolidem na fase adulta. Isso melhora a qualidade de vida das populações futuras e reduz o sedentarismo, gerando menos impacto para a saúde pública (Fontes, Mello, \& Sampaio, 2012).

No Brasil, principalmente para adolescentes de baixa condição socioeconômica a alimentação escolar é primordial, pois muitas vezes é na escola que ele realiza sua principal refeição do dia. As refeições realizadas pelos alunos ao longo do dia constituem o panorama alimentar e indicam o estado nutricional da criança e do adolescente (Mota, Mastroeni, \& Mastroeni, 2013). A qualidade da alimentação é fundamental para garantir a oferta de todos os nutrientes, a fim de ter uma alimentação equilibrada entre os diferentes grupos de alimentos que compõem a pirâmide alimentar e o guia alimentar (Coutinho et al., 2007).

Dietas ricas em lipídeos e carboidratos simples podem ser fatores de risco para obesidade e doenças crônicas, o que ressalta a necessidade de uma avaliação dessa população mediante intervenções e diagnósticos que possibilitem identificar os grupos de riscos e agravos nutricionais (Bertin et al, 2008).

Diante desse contexto o objetivo desse estudo é avaliar a adequação nutricional das refeições consumidas por adolescentes de uma instituição filantrópica de Belo Horizonte. 


\section{Metodologia}

Esse estudo de caso de natureza qualitativa e quantitativa foi realizado em uma instituição integrada e filantrópica, localizada na cidade de Belo Horizonte, Minas Gerais, após autorização do Diretor Pedagógico. Segundo Pereira et al. (2018) o estudo de caso é uma descrição e análise o mais detalhada possível e algum caso que apresente alguma particularidade que o torna especial, como a alimentação dos alunos de 13 a 17 anos dessa instituição. Os métodos qualitativos e quantitativos empregados não se excluem, se complementam e permitem um melhor entendimento do fenômeno em estudo (Yin, 2015).

Todos os alimentos servidos são obtidos por meio de doações para preparar seis refeições ao dia, cinco dias por semana, exceto para aqueles alunos que saem ao final da tarde, que consomem quatro refeições/dia e aqueles que não consomem os lanches oferecidos pela escola, pois trazem de casa. As refeições servidas no local são divididas em: desjejum, servido às 06:30 horas, café da manhã às 09:30 horas, almoço às 12:00 horas, lanche da tarde às 15:30 horas, jantar às 18:30 horas e ceia às 21:00 horas.

Foi realizada a análise qualitativa e quantitativa do cardápio do almoço e lanche, coletando dados de 23 dias, durante o período de 28/08/2019 a 20/10/2019. Utilizou a técnica observacional para organizar e registrar as informações percebidas diretamente, sem qualquer intermediação, durante a execução desse estudo (Pereira et al., 2018).

$\mathrm{Na}$ análise qualitativa do almoço avaliaram-se 20 dias, utilizando o método de Avaliação Qualitativa das Preparações do Cardápio (AQCP). Os itens avaliados foram: presença de frutas in natura e hortaliças folhosa servidas cruas; cores, sendo acatado como repetitiva quando duas preparações eram da mesma cor ou quando havia apenas duas cores na preparação do dia; frituras e doces, estando associados ou não, considerando respectivamente o método de cocção e sobremesas contendo açúcar como principal ingrediente (Proença et al., 2005).

Para os lanches servidos no período da manhã e tarde foi realizada a análise qualitativa durante 23 dias avaliando a presença de: leite e derivados, leite com achocolatado, frutas e doces, conforme preconiza o Guia Alimentar da População Brasileira, que estimula o consumo de alimentos saudáveis, evitando-se os alimentos ricos em açúcares, sódio, gorduras totais e saturadas (Brasil, 2014).

$\mathrm{Na}$ análise nutricional quantitativa do almoço foram analisados os cardápios de sete dias, empregando o método de pesagem direta dos ingredientes utilizados, das preparações e das sobras não consumidas. Os ingredientes, as preparações e as sobras não consumidas foram pesadas na balança Toledo ${ }^{\circledR}$, com capacidade máxima de $30 \mathrm{~kg}$. Os utensílios destinados ao acondicionamento das preparações foram pesados e descontados do peso da preparação. Os temperos e respectivas quantidades utilizados no preparo das refeições: foram $3 \mathrm{~L}$ de óleo, $250 \mathrm{~g}$ de alho e $1 \mathrm{~kg}$ de sal. Utilizou-se a metodologia adotada por Amorim, Junqueira e Jokl (2005): o peso das preparações totais $(\mathrm{P})$ foram deduzidos das respectivas sobras não consumidas (S) para obtenção dos consumos (C) das preparações $(\mathrm{C}=\mathrm{P}$ - S). Os consumos per capita das preparações foram obtidos pela divisão dos consumos totais pelo número de adolescentes servidos por dia $(n=600)$.

As quantidades per capita dos lanches servidos foram: bebidas (um copo de 200mL), pão de batata (uma unidade de 90g), broa de fubá (um pedaço de 100g) e biscoito cream cracker (5 unidades, que equivalem a 32g).

Com base nas quantidades per capita do almoço e lanches foram calculados energia, macronutrientes, fibra, sódio, ferro, magnésio, zinco, vitamina A e C, utilizando Tabela Brasileira de Composição dos Alimentos (NEPA, 2011).

As recomendações nutricionais utilizadas foram as do Programa Nacional de Alimentação Escolar (PNAE), que preconiza $70 \%$ das necessidades diárias, para adolescentes de 11 a 15 anos e de 16 a 18 anos, que permanecem na escola em tempo integral. Para os adolescentes de 11 a 15 anos o valor energético recomendado é $1500 \mathrm{kcal}$, sendo $243,8 \mathrm{~g}$ de carboidrato, 46,9 g de proteína, 37,5 g de lipídeos, 21,1 9g de fibras, $490 \mu \mathrm{g}$ de vit. A, $42 \mathrm{mg}$ de vit. C, $910 \mathrm{mg}$ de cálcio, 7,5 mg de ferro, $222 \mathrm{mg}$ de magnésio e 6,3 mg de zinco. Já para os adolescentes de 16 a 18 anos o valor energético recomendado 
$1700 \mathrm{kcal}$, sendo 276,3 g de carboidrato, $50 \mathrm{~g}$ de proteína, 42,5 g de lipídeos, 22,4 g de fibras, $560 \mu \mathrm{g}$ de vit. A, $49 \mathrm{mg}$ de vit. C, 910 mg de cálcio, 9,1 mg de ferro, $271 \mathrm{mg}$ de magnésio e $7 \mathrm{mg}$ de zinco (Brasil, 2013).

\section{Resultados}

Foram avaliados os cardápios servidos no período de dia 28/08/2019 a 01/09/2019 e 04/09/2019 a 05/09/2019, composto de prato principal, guarnição, arroz, feijão, salada e sobremesa, conforme ilustrado no Quadro 1. Alguns dias da semana nota-se a ausência de uma dessas combinações no cardápio.

Quadro 1. Cardápio mensal do almoço avaliado, na instituição filantrópica, Belo Horizonte, 2019.

\begin{tabular}{|c|c|c|c|c|c|}
\hline \multicolumn{6}{|c|}{$1^{a}$ semana $(28 / 08 / 19$ a $01 / 09 / 2019)$} \\
\hline Refeição & Segunda & Terça & Quarta & Quinta & Sexta \\
\hline Prato principal & Peixe Frito & $\begin{array}{l}\text { Carne cozida } \\
\text { com batata }\end{array}$ & $\begin{array}{l}\text { Carne moída } \\
\text { com batata. }\end{array}$ & $\begin{array}{c}\text { Frango cozido com } \\
\text { batata. }\end{array}$ & $\begin{array}{l}\text { Salsicha com } \\
\text { batata. }\end{array}$ \\
\hline Guarnição & Maionese & - & Polenta & - & - \\
\hline Arroz & Simples & Simples & Simples & Simples & Simples \\
\hline Feijão & Comum & Comum & Comum & Comum & Comum \\
\hline Salada & $\begin{array}{c}\text { Alface com } \\
\text { beterraba }\end{array}$ & $\begin{array}{l}\text { Alface com } \\
\text { tomate e uva } \\
\text { verde } \\
\text { Couve-flor }\end{array}$ & $\begin{array}{l}\text { Alface com } \\
\text { repolho cru e } \\
\text { tomate }\end{array}$ & $\begin{array}{c}\text { Cenoura crua } \\
\text { ralada. } \\
\text { Tomate com pepino }\end{array}$ & $\begin{array}{l}\text { Couve crua } \\
\text { Tomate com } \\
\text { pepino }\end{array}$ \\
\hline Sobremesa & $\begin{array}{c}\text { Chocolate ao } \\
\text { leite }\end{array}$ & Melão & $\begin{array}{c}\text { Chocolate com } \\
\text { recheio de } \\
\text { caramelo }\end{array}$ & Melão & - \\
\hline \multicolumn{6}{|c|}{$2^{a}$ semana-(04/09/2019 a 05/09/2019) } \\
\hline Refeição & Segunda & Terça & \multirow{7}{*}{$\begin{array}{l}\text { Não houve } \\
\text { avaliação }\end{array}$} & \multirow{7}{*}{$\begin{array}{l}\text { Não houve } \\
\text { avaliação }\end{array}$} & \multirow{7}{*}{$\begin{array}{l}\text { Não houve } \\
\text { avaliação }\end{array}$} \\
\hline Prato principal & Peixe assado. & $\begin{array}{l}\text { Canjiquinha } \\
\text { com suã. }\end{array}$ & & & \\
\hline Guarnição & Batata cozida & - & & & \\
\hline Arroz & Simples & Simples & & & \\
\hline Feijão & Comum & Comum & & & \\
\hline Salada & $\begin{array}{l}\text { Alface e } \\
\text { beterraba } \\
\text { cozida }\end{array}$ & $\begin{array}{c}\text { Almeirão cru } \\
\text { Beterraba cozida } \\
\text { Repolho branco } \\
\text { com cenoura } \\
\text { crua }\end{array}$ & & & \\
\hline Sobremesa & $\begin{array}{c}\text { Chocolate ao } \\
\text { leite }\end{array}$ & - & & & \\
\hline \multicolumn{6}{|c|}{$3^{a}$ semana $(11 / 09 / 2019$ a $15 / 09 / 2019)$} \\
\hline Refeição & Segunda & Terça & Quarta & Quinta & Sexta \\
\hline
\end{tabular}


Research, Society and Development, v. 10, n. 1, e54510112052, 2021

(CC BY 4.0) | ISSN 2525-3409 | DOI: http://dx.doi.org/10.33448/rsd-v10i1.12052

\begin{tabular}{|c|c|c|c|c|c|}
\hline Prato principal & $\begin{array}{c}\text { Ovos cozidos } \\
\text { com molho }\end{array}$ & Tropeiro & Peixe assado & $\begin{array}{l}\text { Cubos de frango } \\
\text { cozido }\end{array}$ & $\begin{array}{c}\text { Frango (coxa e } \\
\text { sobrecoxa) } \\
\text { cozido com } \\
\text { batata. }\end{array}$ \\
\hline Guarnição & Angu & Batata Cozida & Purê de batata & $\begin{array}{c}\text { Macarrão ao molho } \\
\text { branco. }\end{array}$ & - \\
\hline Arroz & Simples & Simples & Simples & Simples & Simples \\
\hline Feijão & Comum & - & Comum & Tutu de feijão & Comum \\
\hline Salada & $\begin{array}{c}\text { Alface com } \\
\text { tomate }\end{array}$ & $\begin{array}{c}\text { Couve crua com } \\
\text { tomate }\end{array}$ & $\begin{array}{c}\text { Cenoura crua } \\
\text { Alface com } \\
\text { tomate }\end{array}$ & Alface & $\begin{array}{l}\text { Alface com } \\
\text { tomate }\end{array}$ \\
\hline Sobremesa & - & - & - & - & - \\
\hline \multicolumn{6}{|c|}{$4^{\mathrm{a}} \operatorname{semana}(09 / 10 / 2019$ a $11 / 10 / 219)$} \\
\hline Refeição & Segunda & Terça & Quarta & Quinta & Sexta \\
\hline Prato principal & - & $\begin{array}{l}\text { Estrogonofe de } \\
\text { frango }\end{array}$ & Pernil assado & \multirow{6}{*}{ Não houve aula } & \multirow{6}{*}{ Não houve aula } \\
\hline Guarnição & $\begin{array}{l}\text { Macarrão com } \\
\text { molho branco }\end{array}$ & - & Tropeiro & & \\
\hline Arroz & Simples & Simples & Simples & & \\
\hline Feijão & Comum & - & Comum & & \\
\hline Salada & $\begin{array}{l}\text { Alface com } \\
\text { tomate } \\
\text { Repolho } \\
\text { branco cru, }\end{array}$ & Alface & $\begin{array}{c}\text { Alface com } \\
\text { tomate e pepino. }\end{array}$ & & \\
\hline Sobremesa & - & Maça & $\begin{array}{c}\text { Chocolate ao } \\
\text { leite }\end{array}$ & & \\
\hline \multicolumn{6}{|c|}{$5^{\text {a }}$ semana $(16 / 10 / 2019$ a $20 / 10 / 2019)$} \\
\hline Refeição & Segunda & Terça & Quarta & Quinta & Sexta \\
\hline Prato principal & $\begin{array}{c}\text { Salsicha com } \\
\text { molho de } \\
\text { tomate }\end{array}$ & $\begin{array}{l}\text { Canjiquinha } \\
\text { com suã }\end{array}$ & Peixe assado & Almondega bovina & $\begin{array}{l}\text { Salsicha com } \\
\text { batata cozida }\end{array}$ \\
\hline Guarnição & Angu & - & $\begin{array}{l}\text { Batata com } \\
\text { maionese }\end{array}$ & Farofa & - \\
\hline Arroz & Simples & Simples & Simples & Simples & Simples \\
\hline Feijão & Comum & Comum & Comum & Tutu de feijão & Comum \\
\hline Salada & $\begin{array}{c}\text { Repolho } \\
\text { branco cru } \\
\text { com tomate }\end{array}$ & Alface & $\begin{array}{l}\text { Alface com uva } \\
\text { verde e tomate }\end{array}$ & Alface & $\begin{array}{l}\text { alface com } \\
\text { tomate }\end{array}$ \\
\hline
\end{tabular}




\begin{tabular}{|l|l|l|l|l|l|}
\hline Sobremesa & - & - & - & - & - \\
\hline
\end{tabular}

Fonte: Autores (2020).

Embora a Instituição receba doações de alimentos existe a preocupação de servir diariamente arroz, feijão, prato proteico e salada, compondo uma refeição saudável.

$\mathrm{Na}$ Tabela 1 encontram-se os resultados da análise qualitativa, com o percentual da frequência de ocorrência da presença de frutas, folhosos, cores iguais, doces, frituras, fritura mais doces nos cardápios do almoço.

Tabela 1. Análise qualitativa das preparações dos cardápios do almoço avaliados, na instituição filantrópica, Belo Horizonte, 2019.

\begin{tabular}{llllllcc}
\hline \multicolumn{1}{c}{ Itens analisados } & \multicolumn{9}{c}{ Cardápio Semanal } & $\begin{array}{c}\text { Total } \\
(\text { dias })\end{array}$ & $\begin{array}{c}\text { Ocorrência } \\
(\%)\end{array}$ \\
\hline Frutas & $1^{\mathrm{a}}$ & $2^{\mathrm{a}}$ & $3^{\mathrm{a}}$ & $4^{\mathrm{a}} *$ & $5^{\mathrm{a}}$ & & \\
Folhosos & 3 & 0 & 0 & 1 & 1 & 5 & $25 \%$ \\
Cores Iguais & 5 & 2 & 5 & 3 & 5 & 20 & $100 \%$ \\
Doces & 1 & 0 & 3 & 3 & 2 & 9 & $45 \%$ \\
Fritura & 1 & 1 & 0 & 1 & 0 & 3 & $15 \%$ \\
Fritura + Doce & 0 & 0 & 1 & 1 & 0 & 2 & $10 \%$ \\
* Na 4 & 0 & 0 & 0 & 1 & 0 & 1 & $5 \%$ \\
\hline
\end{tabular}

Fonte: Autores (2020).

Nota-se como pontos positivos da análise qualitativa a presença diária de folhosos e a baixa ocorrência de frituras e doces servidos simultaneamente.

Na Tabela 2 são apresentados os dados referentes às quantidades per capita da salada, arroz, feijão, guarnição, prato principal e sobremesa do almoço analisados durante sete dias.

Tabela 2. Quantidades per capita das preparações consumidas no almoço ofertado na instituição Filantrópica, Belo Horizonte, 2019.

\begin{tabular}{llllllcc}
\hline \multicolumn{1}{c}{ Itens analisados } & \multicolumn{9}{c}{ Cardápio Semanal } & $\begin{array}{c}\text { Total } \\
\text { (dias) }\end{array}$ & Ocorrência (\%) \\
\hline Frutas & $1^{\mathrm{a}}$ & $2^{\mathrm{a}}$ & $3^{\mathrm{a}}$ & $4^{\mathrm{a} *}$ & $5^{\mathrm{a}}$ & & \\
Folhosos & 3 & 0 & 0 & 1 & 1 & 5 & $25 \%$ \\
Cores Iguais & 5 & 2 & 5 & 3 & 5 & 20 & $100 \%$ \\
Doces & 1 & 0 & 3 & 3 & 2 & 9 & $45 \%$ \\
Fritura & 1 & 1 & 0 & 1 & 0 & 3 & $15 \%$ \\
Fritura + Doce & 0 & 0 & 1 & 1 & 0 & 2 & $10 \%$ \\
\hline
\end{tabular}

*Na $4^{\mathrm{a}}$ semana houve somente três dias de aula em decorrência do feriado de 12 de outubro (Semana das Crianças). Fonte: Autores (2020).

As quantidades per capita médias mais consumidas foram o arroz, seguidas do feijão, prato principal, salada, sobremesa e guarnição. 
Os cardápios de cinco semanas, 23 dias, foram utilizados na análise qualitativa, de acordo com a oferta diária dos alimentos que compõem os lanches da manhã e tarde ofertados aos adolescentes. Na Tabela 3 é mostrado os dados da análise qualitativa dos lanches ofertados pela manhã e tarde, com percentual da frequência de ocorrência diária da presença de leite e derivados, leite com achocolatado, frutas e doces nos cardápios analisados.

Tabela 3. Análise qualitativa das preparações dos cardápios dos lanches manhã e tarde avaliados, na instituição filantrópica, Belo Horizonte, 2019.

\begin{tabular}{|c|c|c|c|c|c|c|c|}
\hline \multirow[t]{2}{*}{ Itens analisados } & \multicolumn{5}{|c|}{ Cardápio Semanal } & \multirow{2}{*}{$\begin{array}{l}\text { Total } \\
\text { (dias) }\end{array}$} & \multirow{2}{*}{$\begin{array}{c}\text { Ocorrência } \\
(\%)\end{array}$} \\
\hline & $1^{\mathrm{a}}$ & $2^{a}$ & $3^{a}$ & $4^{\mathrm{a} *}$ & $5^{a}$ & & \\
\hline Leite e derivados & 5 & 5 & 5 & 3 & 5 & 23 & $100 \%$ \\
\hline Leite com achocolatado & 4 & 5 & 3 & 2 & 2 & 17 & $74 \%$ \\
\hline Frutas & 0 & 0 & 0 & 2 & 0 & 2 & $9 \%$ \\
\hline Doces & 0 & 0 & 0 & 0 & 0 & 0 & $0 \%$ \\
\hline
\end{tabular}

*Na $4^{\text {a }}$ semana houve somente três dias de aula em decorrência do feriado.

Fonte: Autores (2020);

Observa-se como ponto positivo a presença diária de leite e derivados, fonte de cálcio e a ausência de doces, fonte de calorias vazias.

Na Tabela 4 estão descritos os valores médios do consumo de macronutrientes (carboidrato, proteína, lipídeo), energia, fibra e micronutrientes (sódio, ferro, magnésio, zinco, vitamina A e vitamina C) e os respectivos percentuais de adequação, dos adolescentes de 11 a 15 anos e de 16 a 18 anos, que permanecem na instituição, no período de 7:00 horas às 17:00 horas. 
Tabela 4. Consumo de macronutrientes, energia, fibra e micronutrientes ofertados nas três refeições/dia, na instituição filantrópica, Belo Horizonte, 2019.

\begin{tabular}{|c|c|c|c|c|c|c|c|c|c|c|c|}
\hline Dias & $\begin{array}{l}\text { Carboidrato } \\
\text { (g) }\end{array}$ & $\begin{array}{c}\text { Proteína } \\
(\mathrm{g})\end{array}$ & $\begin{array}{l}\text { Lipídeo } \\
\text { (g) }\end{array}$ & $\begin{array}{c}\text { Energia } \\
\text { (kcal) }\end{array}$ & $\begin{array}{c}\text { Fibra } \\
(\mathrm{g})\end{array}$ & $\begin{array}{l}\text { Sódio } \\
(\mathrm{mg})\end{array}$ & $\begin{array}{l}\text { Ferro } \\
(\mathrm{mg})\end{array}$ & $\begin{array}{l}\mathrm{Mg} \\
(\mathrm{mg})\end{array}$ & $\begin{array}{l}\text { Zinco } \\
(\mathrm{mg})\end{array}$ & $\begin{array}{l}\text { VitA } \\
\text { (ug) }\end{array}$ & $\begin{array}{l}\text { VitC } \\
(\mathrm{mg})\end{array}$ \\
\hline 28/ago & 207,6 & 35,7 & 47,4 & 1399,8 & 14,3 & 1656,7 & 8,1 & 182,4 & 4,1 & 363,0 & 31,6 \\
\hline 29/ago & 188,4 & 40,3 & 27,0 & 1158,0 & 11,9 & 968,3 & 7,6 & 158,8 & 8,4 & 169,0 & 43,5 \\
\hline 30/ago & 150,3 & 27,3 & 38,4 & 1056,0 & 11,6 & 1668,0 & 8,5 & 168,2 & 4,9 & 80,1 & 21,9 \\
\hline 31/ago & 173,8 & 34,6 & 32,7 & 1127,9 & 14,2 & 1605,7 & 8,3 & 165,4 & 4,1 & 501,0 & 32,4 \\
\hline 01/set & 194,8 & 34,0 & 36,9 & 1247,3 & 14,5 & 1811,7 & 7,9 & 162,4 & 4,1 & 203,5 & 52,8 \\
\hline 04/set & 124,0 & 31,4 & 19,8 & 800,0 & 9,6 & 1805,0 & 7,2 & 132,2 & 2,9 & 63,6 & 17,5 \\
\hline 05/set & 187,4 & 33,5 & 36,7 & 1214,1 & 12,1 & 728,9 & 6,8 & 145,2 & 4,9 & 307,2 & 5,9 \\
\hline Média & 175,2 & 33,8 & 34,2 & 1143,3 & 12,6 & 1463,4 & 7,8 & 159,2 & 4,7 & 241,1 & 29,4 \\
\hline $\begin{array}{c}\text { Adequação } \\
\text { adolescentes } \\
11 \text { a 15 anos } \\
\text { (\%) }\end{array}$ & 71,8 & 72,1 & 91,1 & 76,2 & 59,6 & 243,9 & 103,7 & 71,7 & 75,3 & 49,2 & 69,9 \\
\hline $\begin{array}{c}\text { Adequação } \\
\text { adolescentes } \\
16 \text { a 18 anos } \\
(\%) \\
\end{array}$ & 63,4 & 67,7 & 80,4 & 67,3 & 2,8 & 243,9 & 85,4 & 58,8 & 67,7 & 43,0 & 59,9 \\
\hline
\end{tabular}

Fonte: Os autores (2020)

Nota-se que a adequação nutricional dos macronutrientes e micronutrientes para os adolescentes de 11 a 15 anos apresentou melhores percentuais em relação aos adolescentes de 16 a 18 anos.

\section{Discussão}

Ao observar o cardápio do almoço (Quadro 1), nota-se que em todos os dias houve oferta de vegetais folhosos nos cardápios (Tabela 1), resultado semelhante ao encontrado na pesquisa AQPC realizada por Ygnatios, Lima, e Pena, (2017) em uma escola privada de um município do interior de Minas Gerais. Valores inferiores (43,9\%) foram apresentados por Muniz et al. (2013) em um estudo realizado com adolescentes de 14 a 19 anos, em Caruaru, Pernambuco. Deve se preconizar o consumo desses alimentos nas refeições, pois a baixa ingestão pode indicar deficiência de vitaminas, sais minerais e fibras. De modo geral, as preparações da salada deixaram a desejar, deveriam ser mais coloridas, nutritivas e atraentes.

Quanto às frutas servidas como sobremesa, percebe-se que são pouco ofertadas (Tabela 1). No estudo realizado com adolescentes de baixo nível socioeconômico de um Centro de Juventude no município de São Paulo, foi identificado que as frutas somente eram consumidas nas refeições realizadas na instituição (Garcia, Gambardella \& Frutuoso, 2003). No estudo realizado por Horta, Ferreira e Santos (2012) foi mostrado maior aceitação das frutas em relação às hortaliças. Segundo Muniz et al. (2013) no estudo realizado com adolescentes de 14 a 19 anos, em Caruaru, Pernambuco, o consumo de frutas (56\%) foi superior ao do presente estudo. Como os adolescentes deste estudo permanecem na instituição em tempo integral, destaca-se a importância de aumentar a oferta de frutas, pois a escola influencia na formação de hábitos alimentares saudáveis.

As preparações dos cardápios tiveram repetições de cores (Tabela 1) em $45 \%$ dos dias avaliados. Valores similares (40\%) foram encontrados por Ygnatios, Lima e Pena, (2017) no almoço de um cardápio escolar analisado. As cores de uma preparação estão envolvidas com o aspecto visual do prato que podem contribuir para estimular o seu consumo, tornando a alimentação atrativa, além de contribuir para a ingestão de micronutrientes (Proença et al. 2005). 
$\mathrm{Na}$ instituição filantrópica avaliada foram servidos três vezes fritura e doce no cardápio, durante cinco semanas, e doce junto com fritura apenas uma ocorrência (Tabela 1). Os doces são servidos como sobremesa do almoço apenas quando há doações, e em dias letivos comuns não são preparados, apenas no Natal e Páscoa, uma conduta positiva pois limita o consumo de açúcares. O Guia Alimentar para População Brasileira estabelece que açúcares devem ser usados em pequenas quantidades, pois contribui para elevar o risco de cárie dental, obesidade e diversas outras doenças crônicas (Brasil, 2014).

Com relação à média do consumo per capita do almoço (Tabela 2) foi encontrado 349,85 g, valor superior (323,25 g) ao encontrado por Issa et al. (2014), no estudo realizado em 42 escolas municipais integradas de Belo Horizonte, na faixa etária de 6 a 15 anos. Os valores das quantidades per capita das preparações consumidas na escola variaram, para o arroz: de 87,93g a 116,37 g, feijão: $73,18 \mathrm{~g}$ a $94,95 \mathrm{~g}$, carne: $24,86 \mathrm{~g}$ a $96,53 \mathrm{~g}$, salada: $19,86 \mathrm{~g}$ a $63,08 \mathrm{~g}$. O consumo de guarnição foi menor em comparação as outras preparações, com variação per capita entre $9,6 \mathrm{~g}$ e $96,11 \mathrm{~g}$.

$\mathrm{Na}$ análise qualitativa dos lanches (Tabela 3), observa-se que todos os dias foi ofertado na escola o leite, associado ao café e ao achocolatado, e eventualmente iogurte e vitamina de frutas com leite. Embora não seja servido doces, há a oferta de achocolatado em quase todos os dias (74\%), uma prática não saudável, por ser o achocolatado um alimento rico em açúcar, cujo consumo deve ser evitado, como preconiza o Guia Alimentar para a População Brasileira (Brasil, 2014). Horta, Ferreira, \& Santos (2012) analisaram a preferência de adolescentes, de uma escola da rede pública de Belo Horizonte, por leite e derivados, e descobriram consumo insuficiente de leite, apesar de verificar grande preferência, sugerindo, pouca disponibilidade no meio familiar, devido ao custo e do não entendimento da importância de ingestão adequada destes alimentos.

Em relação às frutas (Tabela 3) percebe-se que é baixa a oferta nos lanches da manhã e tarde (9\%). Um estudo desenvolvido por Silva et al. (2015), com adolescentes do nordeste do Brasil, também mostrou consumo inadequado de frutas e hortaliças (11,4\%). Resultado também baixo (18\%) foi encontrado no Estudo de Riscos Cardiovasculares em Adolescentes de 12 a 17 anos, realizado em 2013-2014. Dentre os 20 alimentos mais consumidos, somente os meninos entre 12 a 13 anos apontaram as frutas (Sousa et al., 2016). A Pesquisa Nacional de Saúde do Escolar realizada, em 2015, indicou entre os estudantes brasileiros um percentual de 32,7\% referente ao consumo semanal de frutas frescas (IBGE; 2016).

Quanto aos macronutrientes (Tabela 4), nenhum atingiu a recomendação diária do PNAE. O percentual de adequação para as faixas etárias de 11 a 15 anos e de 16 a 18 anos, foram respectivamente, para carboidratos $71 \%$ e $63,4 \%$, proteínas $72,1 \%$ e $67,7 \%$ e lipídeos $91,1 \%$ e $80,4 \%$. Um estudo de uma escola pública municipal na cidade de Bezerro (PE), que avaliou a merenda ofertada para estudantes do $5^{\circ}$ ao $9^{\circ}$ ano, mostrou valores superiores para carboidratos $(125,54 \%)$ e proteínas (117,86\%), e semelhantes para lipídeos (91,85\%) (Silva \& Fernandes, 2014).

O valor energético médio (Tabela 4) não atingiu a recomendação de 70\% preconizada pelo PNAE. Percebe-se que a ingestão energética se encontra menor principalmente entre os alunos que são de maior idade, sendo 76,2\% para os de 11 a 15 anos e 67,3\% para os de 16 a 18 anos. Resultado inadequado, também foi encontrado por Silva (1998), em um estudo com alunos dos Centros Integrados de Educação Pública, em Americana (SP). Ao se comparar a ingestão energética ofertada pela escola descobriu que os alunos de maior faixa etária, tinham os piores índices de ingestão, sendo para os grupos de 9 a 10 anos 56\% e para os grupos de 13 anos ou mais 59\% (Silva, 1998). Essa diferença de adequação para as faixas etárias, também foi observado por Silva \& Gregório (2011), que concluíram que devido os cardápios e a porção serem iguais e não diferenciados por idade, ocorre essa dificuldade de adequação dos nutrientes. Como foi avaliado o consumo médio seria conveniente realizar um estudo com o consumo individual, com a finalidade de melhor avaliar as necessidades tanto de energia como de nutrientes para as faixas etárias distintas (Silva, 1998; Silva \& Gregório; 2011). 
Em relação às fibras (Tabela 4) nota-se que não alcançou a recomendação do PNAE para ambas faixas etárias (12,6 g). Baixo consumo de fibras também foi observado por Issa et al. (2014) que obtiveram valor médio de 4,70g, sendo bem inferior ao deste estudo.

O sódio obteve valores variados entre as refeições (Tabela 4), e o consumo médio diário em período integral foi superior em 4,50\% à recomendação preconizada pelo PNAE para ambas faixas etárias. Vale ressaltar que a instituição não utiliza condimentos industrializados, considerada uma prática saudável, contudo deve diminuir a quantidade de sal adicionada às refeições, que é de 1,2 mg. Um excesso de consumo de sódio também foi encontrado no estudo de Reis, Sousa \& Messias (2016) em uma escola pública de Pernambuco com alunos de 15 a 17 anos de ambos os sexos, no qual os adolescentes do sexo masculino apontaram uma média de ingestão superior a 2.813,24 mg e as do sexo feminino uma taxa superior a 3,038,53 mg. Segundo Dias et al. (2012) o excesso de sódio é uma das causas mais relevantes para o surgimento da hipertensão arterial, que tem aumentado a incidência entre crianças e adolescentes (Reis, Sousa \& Messias, 2016; Dias et al., 2012).

O ferro teve variações no consumo entre $6,8 \mathrm{mg}$ e $8,5 \mathrm{mg}$ não atingindo as recomendações do PNAE para adolescentes da faixa etária entre 16 a 18 anos (Tabela 4). No estudo de Leal et al. (2010) de avaliação do consumo alimentar de adolescentes em São Paulo, o ferro ultrapassou a recomendação para a maioria dos adolescentes, pois era ofertado alimentos dos grupos dos feijões e carnes. Pioltine e Spineli (2012) incentivam a ingestão de ferro nas refeições, optando por carnes, pois, as deficiências dos minerais ferro e zinco estão relacionadas à baixa ingestão desses alimentos.

O magnésio consumido (159,2 mg) não atingiu o recomendado pelo PNAE necessário para ambas faixas etárias (Tabela 4). Segundo Batista et al. (2016) ao avaliar o consumo alimentar de magnésio por adolescentes com idade entre 15 a 17 anos em uma escola pública em Petrolina (PE) houve a inadequação do consumo alimentar (96,2mg). O inadequado consumo de magnésio nas escolas públicas pode estar relacionado a falta de alimentos como cereais integrais, vegetais folhosos verdes, frutas, legumes e tubérculos. O baixo consumo desse mineral expõe os indivíduos a um risco de adquirir doenças crônicas, resistência à insulina, diabetes mellitus tipo II e doenças cardiovasculares. Em nosso estudo o baixo consumo de magnésio também está relacionado a pouca oferta desses alimentos nas preparações, pois, a escola vive de doação e nem sempre ganham alimentos ricos em magnésio.

Os valores encontrados de 4,7 mg de zinco (Tabela 4) foram insuficientes para as duas faixas etárias, com percentual de adequação de 75,3\% para adolescentes de 11 a 15 anos e 67,7 \% para 16 a 18 anos. Issa et al. (2014) também identificaram inadequações nutricionais no cardápio consumido por alunos de 11 a 15 anos, cujo o consumo de zinco era de 1,70 g. O metabolismo do hormônio do crescimento pode ser afetado pela deficiência desse mineral (Issa et al., 2014)

Com relação a vitamina A (Tabela 4), observa-se que média diária não atingiu as indicações do PNAE, sendo o menor percentual, nas duas faixas etárias, quando relacionado com os outros nutrientes (49,2\% e 43\%). Essa constatação é um fator crítico, em virtude da vitamina A ser essencial para o crescimento e maturação sexual, e o seu baixo consumo, assim como de outras vitaminas fundamentais na adolescência, pode acarretar em distúrbios nutricionais que irão interferir desenvolvimento (Giannini, 2007).

A vitamina C (Tabela 4) não atingiu a recomendação do PNAE para ambas faixas etárias. Estudos realizados por Silva, Mendes e Messias (2015) apontam uma prevalência de inadequação de vitamina C em ambos os sexos, de uma escola pública em Petrolina (PE), com a maior prevalência nas adolescentes de 10 a 14 anos.

\section{Conclusão}

A partir dos resultados obtidos com o presente estudo, sobre o consumo alimentar dos adolescentes, foi possível notar que alguns resultados foram semelhantes a estudos já realizados sobre a alimentação dos adolescentes, mostrando a baixa ingestão de frutas, o consumo de forma inadequada do leite, visto que o mesmo é ingerido diariamente, porém com 
achocolatado. As vitaminas e minerais como a vitamina A, C, magnésio, zinco e as fibras também ficaram abaixo do preconizado pelo PNAE, o que evidencia a baixa ingestão de vegetais folhosos, e legumes na alimentação. Quanto à ingestão de macronutrientes nota-se que nenhum deles atingiu o percentual de adequação para as faixas etárias conforme também preconiza o PNAE. As principais fontes de energia, como os carboidratos e lipídeos tiveram baixo consumo. O percentual de ingestão de proteínas foi o mais baixo entre os macronutrientes o que consequentemente influencia a baixa ingestão de ferro sem distinção de gênero.

Assim percebe- se a necessidade de ações eficientes que incentivem a maior ingestão de uma alimentação balanceada e equilibrada para os adolescentes nas escolas integrais, mesmo em instituições filantrópicas, a fim de garantir o estado nutricional promovendo a saúde dos adolescentes, gerando hábitos alimentares mais saudáveis, prevenindo futuras doenças crônicas não transmissíveis.

Nesse estudo de caso foi avaliado o consumo alimentar per capita médio dos adolescentes de diferentes idades traçando um panorama geral da adequação nutricional. Assim sugere-se realizar um estudo avaliando separadamente o consumo alimentar médio per capita de cada grupo de adolescentes, de 11 a 15 anos e de 16 a 18 anos, proporcionando uma adequação nutricional mais individualizada.

\section{Referências}

Amorim, M. M. A., Junqueira, R. G., \& Jokl, L. (2005) Adequação nutricional das refeições do almoço self service de uma empresa de Santa Luzia, MG. Revista de Nutrição, 18(1), 145-156. https://doi.org/10.1590/S1415-52732005000100013.

Batista, A. M., Silva, E. M., Silva, E. I. G., \& Messias, C. M. B. O. (2016). Consumo alimentar de magnésio, potássio e fósforo por adolescentes de uma escola pública. Revista Saúde e Pesquisa, 9(1), 73-82. http://dx.doi.org/10.177651/1983-1870.2016v9n1p73-82.

Bertin, L. R. et al. (2008). Estado nutricional e consumo alimentar de adolescentes da rede pública de ensino da cidade de São Mateus do Sul. Rev. Bras. Saude Mater. Infant., 8 (4), 435-443. https://doi.org/10.1590/S1519-38292008000400009.

Coutinho, N. M. P, Valões, E. M., Lacerda, N. C., \& Menezes, D. N. (2007). Avaliação nutricional e consumo de alimentos entre adolescentes de risco. Rev RENE, 8 (3), 9-16. http://www.repositorio.ufc.br/handle/riufc/13478.

Dias, L. C. D., Cintra, R. M. G. C., Souza, J. T., \& Aranha, C. G. S. (2012). Valor nutricional da alimentação escolar oferecida em uma rede municipal de ensino. Revista Ciência em Extensão, 8(2), 134-143.

Fontes, G. A. V., Mello, A. L., \& Sampaio, L. R. (2012). Manual de avaliação nutricional e necessidade energética de crianças e adolescentes uma pratica aplicada: EDUFBA.

Garcia, G. C. B., Gambardella, A. M. D., \& Frutuoso M. F. P. (2003). Estado nutricional e consumo alimentar de adolescentes de um centro de juventude da cidade de São Paulo. Revista de Nutrição, 16(1), 41-50. http://dx.doi.org/10.1590/S1415-52732003000100005.

Giannini, D. T. (2007.). Recomendações nutricionais do adolescente. Revista Adolescência \& Saúde, 4(1), 12-18. https://cdn.publisher.gn1.link/adolescenciaesaude.com/pdf/v4n1a03.pdf.

Horta, P. M., Ferreira, A. D., \& Santos, L. C. (2012). Impacto de um programa de educação nutricional em adolescentes estudan tes da rede pública. Rev. APS, $15(2), 185-191$

Instituto Brasileiro de Geografia e Estatística. IBGE (2016). Instituto Brasileiro de Geografia e estatística. Pesquisa nacional de saúde do escolar: 2015 / IBGE, Coordenação de População e Indicadores Sociais. - Rio de Janeiro, IBGE, 132 p. file:///C:/Users/lenovo/Downloads/liv97870.pdf.

Issa, R. C., Moraes, L. F., Francisco, R. R. J., Santos, L. C., Anjos, A. F. V., \& Pereira, S. C. L. (2014). Alimentação escolar: planejamento, produção, distribuição e adequação. Revista Panamericana de Salud Publica, 35(2), 96-103. https://www.scielosp.org/article/ssm/content/raw/?resou rce_ssm_path=/media/assets/rpsp/v35n2/a03v35n2.pdf.

Leal, G. V. S., Philippi, S. T., Matsudo, S. M. M., \& Toassa, E. C. (2010). Consumo alimentar e padrão de refeições de adolescentes, São Paulo, Brasil. Revista Brasileira de Epidemiologia 13(3), 457-67. https://doi.org/10.1590/S1415-790X2010000300009.

Ministério da Educação (2013). Resolução/CD/FNDE n. 26, de 17 de junho de 2013. Dispõe sobre o atendimento da alimentação escolar aos alunos da educação básica no âmbito do Programa Nacional de Alimentação Escolar (PNAE). Brasília, DF. https://www.fnde.gov.br/fndelegis/action/Url PublicasAction.php?acao=abrirAtoPublico\&sgl_tipo=RES\&num_ato=00000026\&seq_ato=000\&vlr_ano=2013\&sgl_orgao=FNDE/MEC

Ministério da Saúde (2014). Secretaria de Atenção à Saúde. Departamento de Atenção Básica. Guia Alimentar para a População Brasileira. (2ª ed.).

Mota, H. C., Mastroeni, S. S. B. S., \& Mastroeni, F. M. (2013). Consumo da refeição escolar na rede pública municipal de ensino. Revista Brasileira de Estudos Pedagógicos, 94 (236), 168184. http://dx.doi.org/10.1590/S2176-66812013000100009. 
Research, Society and Development, v. 10, n. 1, e54510112052, 2021

(CC BY 4.0) | ISSN 2525-3409 | DOI: http://dx.doi.org/10.33448/rsd-v10i1.12052

Muniz, L. C., Zanini, R. V., Schneider, B. C., Tassitano, R. M., Feitosa, W. M. N., \& GonzálezChica, D. A. (2013). Prevalência e fatores associados ao consumo de frutas, legumes e verduras entre adolescentes de escolas públicas de Caruaru, PE. Revista Ciência \& Saúde Coletiva, 18(2), 393-404. https://doi.org/10.1590/S1413-81232013000200011

Núcleo de Estudo e Pesquisas em Alimentação [NEPA] (2011). Tabela Brasileira de Composição de Alimentos: NEPA, UNICAMP.

Pereira, A, S.; Shitsuka, D.M.; Parreira, F.J.; Shitsuka, R. Metodologia da pesquisa científica. UFSM, NTE, $2018 . \quad 1$ e-book. https://repositorio.ufsm.br/bitstream/handle/1/15824/Lic_Computacao_Metodologia-Pesquisa-Cientifica.pdf?sequence=1.

Pioltine, M., \& Spinelli, M. G. N. (2012) Análise da oferta alimentar em uma escola privada do município de São Paulo. Revista Univap, 18(31), 48-57. https://doi.org/10.18066/revuunivap.v.18i31.62.

Proença, R. P. C., Sousa, A. A., Vieiros, M. B., \& Hering B. (2005). Qualidade Nutricional e Sensorial na Produção de Refeições. UFSC, 91-93.

Reis, I. R. M. S., Sousa, H. M. S., \& Messias, C. M. B. O. (2016). Comparação do consumo de sódio e fibras entre adolescentes de ambos os sexos. Revista Baiana de Saúde Pública, 40 (4), 957-967. https://doi.org/10.22278/2318-2660.2016.v40.n4.a2080.

Santana, R. F., Oliveira, A. P., Araújo, D. E., Miranda, A. S., \& Santos, R. N. (2015). Intervenções de educação alimentar e nutricional para crianças de uma fundação pública em vitória da conquista - BA: construindo novos hábitos alimentares. Revista Extendere, 3(1), 1-12. http://periodicos.uern.br/index.php/extendere/article/view/1630/883.

Silva, E. I. G., Mendes, M. L. M., \& Messias, \& C. M. B. O. (2015). Consumo alimentar das vitaminas A, C, B9 e de Zinco por adolescentes de uma escola pública. Revista Baiana de Saúde Pública, 39(3): 598-616. 10.5327/Z0100-0233-2015390300010

Silva, M. M. D. C., \& Gregório, E. L. (2011). Avaliação da composição nutricional dos cardápios da alimentação escolar das escolas da rede municipal de Taquaraçu de Minas - MG. Revista HU, 37(3), 387-394.

Silva, M. V. (1998). Alimentação na escola como forma de atender às recomendações nutricionais de alunos dos Centros Integrados de Educação Pública (CIEPS). Caderno de Saúde Pública, 14(1), 171-180. http://dx.doi.org/10.1590/S0102-311X1998000100025

Silva, R. G., \& Fernandes, T. F. S. (2014). Valor nutricional da merenda oferecida em uma escola municipal do agreste pernambucano. Rev. Baiana de Saúde Pública. 38(2), 404-416. https://doi.org/ 10.5327/Z0100-0233-2014380200013.

Sousa, A. M. et al. (2016). ERICA: ingestão de macro e micronutrientes em adolescentes brasileiros. Rev. Saúde Pública, 50(suplem 1), 5s. http://dx.doi.org/10.1590/S01518-8787.2016050006698.

Ygnatios, N. T. M., Lima, N. N., \& Pena, G. G. (2017). Avaliação qualitativa das preparações do cardápio de uma escola privada em um município do interior de Minas Gerais. RASBRAN - Revista da Associação Brasileira de Nutrição, 8(1), 82-89. https://rasbran.emnuvens.com.br/rasbran/article/view/580/163

Yin, R. K. (2015). O estudo de caso: Bookman. 